\title{
PERCEPÇÃO DE ALUNOS E PROFESSORES DE ENFERMAGEM QUANTO AO DESENVOLVIMENTO DA COMPETÊNCIA ATENÇÃO À SAÚDE
}

\author{
Larissa Sapucaia Ferreira Esteves, Danilo Tonietti \\ Universidade do Oeste Paulista - UNOESTE, Curso de Enfermagem, Presidente Prudente, SP. e-mail: \\ larissaesteves@unoeste.br
}

\begin{abstract}
RESUMO
Este estudo teve por objetivo analisar o papel do Estágio Curricular Supervisionado (ECS) no desenvolvimento de uma das competências básicas posta pelas Diretrizes Curriculares Nacionais para os cursos de graduação em enfermagem, a competência Atenção à Saúde. Trata-se de pesquisa quantiqualitativa de estudo de caso. Os sujeitos foram os atores envolvidos com a dinâmica do estágio, ou seja, estudantes do último semestre da graduação e docentes. A coleta de dados se deu por meio da aplicação de questionário semiestruturado, que gerou dados objetivos e dados subjetivos. Para a análise dos dados utilizou-se da estatística descritiva e da análise de conteúdos. Das ações realizadas no dia a dia, três foram significativas para o desenvolvimento da competência Atenção à Saúde, sendo elas: relação com outros serviços da rede de atenção à saúde, resolução de problemas em âmbito individual e/ou coletivo e atividades de caráter técnico. A análise dos dados mostrou que o desenvolvimento de competências vai além da realização repetitiva de ações. Conclui-se que estudantes e docentes consideram que esta competência foi desenvolvida durante a realização do estágio.

Palavras-chave: competência profissional, prática profissional, ensino, educação em enfermagem, atenção à saúde.
\end{abstract}

\section{NURSING STUDENTS AND PROFESSORS' PERCEPTIONS TOWARDS THE DEVELOPMENT OF ATTENTION HEALTH CARE}

\begin{abstract}
The present paper analyses the role of the Supervised Curricular Internship in the development of "Attention to Health", one of the basic competences to be developed by a Nursing graduation course, according to the "National Curricular Guidelines". It is a qualitative and quantitative case study, where the subjects were the actors involved in the dynamics of the internship: last-year undergraduates and lecturers. Data was collect through a semi-structured questionnaire, which generated subjective and objective data, examined via descriptive statistics and via contents analysis. Three of the actions normally performed in the daily practice of the internship had a significant impact in the development of "Attention to Health": the relationship with other services within the healthcare system, the solution of individual and/or collective problems, and technical activities. The data collected shows that the development of competences goes beyond the performing of repetitive actions. The conclusion is that both last-year undergraduates and lecturers believe that the above mentioned competence was developed during the internship.
\end{abstract}

Keywords: professional ability, professional practice, teaching, nursing education, health care.

\section{INTRODUÇÃO}

Desde a instituição das Diretrizes Curriculares Nacionais (DCN) ${ }^{1}$ no final do ano de 2001, as Escolas e Faculdades de Enfermagem no Brasil se tornaram palco para debates acerca do desenvolvimento de competências profissionais. Com a promulgação da Lei de Diretrizes e Bases para a Educação ${ }^{2}$, os currículos mínimos que norteavam a formação, foram extintos e substituídos por diretrizes curriculares que trouxeram orientações gerais a serem observadas e implementadas nos cursos de graduação por meio de seus projetos político-pedagógicos. 
As DCN, por meio do estabelecimento de competências para o profissional enfermeiro, expressaram o movimento por mudanças que ocorreu na educação e na saúde, reforçando o compromisso com os princípios da Reforma Sanitária Brasileira e com Sistema Único de Saúde (SUS), dando autonomia aos cursos para construir, coletivamente, seus Projetos Pedagógicos, respeitando as especificidades regional, local e institucional ${ }^{3}$.

Ao estabelecer

competências

profissionais, as DCN adentraram em um paradigma contraditório e repleto de conceitos. Para alguns autores ${ }^{4}$ quando se fala em desenvolvimento de competências, o ensino superior tem oscilado entre 0 ato de ensinar conhecimentos (pedagogia tradicional) ou voltado para desenvolver competências (pedagogias ativas).

Ao direcionar a formação profissional para atender à demanda do mercado de trabalho, que no caso da enfermagem, atende a demanda de saúde, o desenvolvimento de competências profissionais passou a ser tratado como resultados esperados pelos processos formativos. No entanto, conceitualmente, o termo competência profissional ainda não se encontra bem definido. Atualmente, vários são os estudos que se debruçam sobre a temática a fim de trazer um significado que possa ser capaz de expressar a amplitude desse conceito ${ }^{5}$.

As DCN $^{1}$ deixam claro o perfil dos profissionais que o país necessita para que os sistemas de saúde possam ser organizados, conduzidos e produzirem os resultados necessários para melhoria dos indicadores de saúde. Neste sentido, traz em seu texto, de forma simplista (habilidades), as competências profissionais necessárias ao perfil almejado.

A noção de competências ${ }^{4}$ está intimamente atrelada às ações que os indivíduos executam no desenvolvimento de suas profissões, mas embora atualmente o debate gire em torno da complexidade de ações e processos mentais que são mobilizados em ação para certificar a competência profissional ${ }^{6}$, este trabalho parte do pressuposto que as competências profissionais trazidas pelas DCN podem ser habilidades e que ao serem executadas várias vezes, podem ser desenvolvidas. A base para esta afirmação partiu de Perrenoud" em que defende "as competências como aquisições, aprendizados construídos".
Foi possível utilizar de tal conceito, pois este trabalho não pretende desvendar os caminhos percorridos pelas escolas na construção de competências profissionais, mas identificar se as competências trazidas pelas DCN podem ser desenvolvidas por meio da repetição de ações que sustentam o fazer profissional dentro de cada uma delas.

A escolha pela competência atenção à saúde neste artigo deu-se por considerar que a mesma é a finalidade do trabalho assistencial do enfermeiro. Para desenvolver esta competência, - profissional faz uso de seu principal instrumento: o cuidar. No cuidar, o enfermeiro mobiliza vários processos de trabalho como o assistir, o administrar ou gerenciar, o pesquisar e o ensinar ${ }^{8}$, permitindo então que a essência da profissão seja cumprida.

Para fomentar o desenvolvimento de competências profissionais, as $\mathrm{DCN}^{1}$ preveem, também, atividades práticas supervisionadas desde o início do curso. O objetivo de colocar o aluno em campo é proporcionar o contato com a realidade da profissão, refletindo acerca do ser, do conhecer e do fazer. Esta aproximação visa à superação da dicotomia entre o mundo idealista da escola e o mundo real do trabalho.

No curso estudado, inicialmente, o aluno adquire conhecimentos e desenvolve habilidades e atitudes relacionadas às bases da profissão, os fundamentos profissionais são explorados a fim de capacitá-lo ao exercício profissional reflexivo e com criticidade. No decorrer do curso, outros conhecimentos, habilidades e atitudes mais complexas são desenvolvidas partindo do pressuposto de que a maturidade do estudante $o$ auxiliará nos processos mentais necessários para a compreensão da profissão. Por fim, o aluno, agora mais autônomo, experimenta a prática profissional de forma tutorada, permitindo que estabeleça relações de troca com os profissionais de campo e que possa "testar" e aprimorar as habilidades e conhecimentos adquiridos nos anos anteriores.

A prática tutorada é chamada de Estágio Curricular Supervisionado (ECS) e acontece nos dois últimos anos da graduação conforme estabelecido nas $D_{C N}{ }^{1}$. Distingue-se das demais atividades teórico-práticas, pois permite a atuação do futuro profissional de forma mais independente, consciente e responsável. Com intenção interativa, o aluno é desafiado a colocar-se criticamente frente à realidade da profissão. 
A participação do discente no cotidiano do trabalho do enfermeiro se apresenta na perspectiva de uma efetiva articulação que contribui não só para a formação profissional, mas também para as mudanças na produção de serviços. A realidade concreta, experimentada pelo aluno por meio do ECS, é peça fundamental para $\mathrm{o}$ processo ensino-aprendizagem e possibilita compreensão ampla e profunda das dificuldades vividas pela profissão ${ }^{3}$.

Sendo assim, a hipótese defendida por esta pesquisa foi: o ECS de Enfermagem possibilita o desenvolvimento das competências do futuro enfermeiro, por meio da realização frequente de ações que as embasam.

Na tentativa de provar esta hipótese, a compreensão sobre o desenvolvimento das competências veio pelo relato dos atores do processo: o aluno e o professor. A discussão das ações mais significantes que foram desenvolvidas no dia a dia do ECS, auxiliou na avaliação do processo ensino-aprendizagem do curso.

Neste sentido, o presente estudo teve como objetivo identificar se as ações realizadas durante 0 ECS que contribuíram para 0 desenvolvimento, ou não, da competência atenção à saúde, segundo a percepção dos alunos e dos professores de uma das turmas do referido estágio.

\section{METODOLOGIA}

Esta pesquisa trata-se de um estudo de caso (pois permite buscar os significados atribuídos pelos sujeitos às ações em questão, incluindo valores, aspirações e motivações) de caráter quanti-qualitativo ${ }^{9}$.

A análise quantitativa se deu por meio da estatística descritiva que permitiu identificar se as ações que contribuíram para o desenvolvimento das competências estão relacionadas com a frequência com que cada aluno realizou cada uma delas. E a análise qualitativa permitiu compreender de forma mais subjetiva os resultados da análise quantitativa.

Para o procedimento de coleta de dados, foi utilizado um questionário semiestruturado. $O$ questionário foi construído sob á luz das DCN para os cursos de graduação em enfermagem e contava com perguntas fechadas e perguntas abertas. Foram utilizados dois tipos de questionários: um voltado para os alunos; e outro voltado para os docentes.

A população estudada constituiu-se de: alunos e professores do último semestre da graduação do curso estudado que realizaram o ECS no 20 semestre de 2010 . Faziam parte desta turma de estágio 120 alunos e 12 docentes e, para garantir que os dados pudessem ser analisados também de forma quantitativa, procuramos selecionar os sujeitos de cada um dos segmentos envolvidos e obter a representatividade por meio da participação de $25 \%$ da população, ou seja, 30 alunos e quatro docentes. Todos os sujeitos foram abordados após aprovação pelo Comitê de Ética e Pesquisa da Universidade (CAAE 30652714.7.0000.5515) e participaram da pesquisa após autorização por meio do Termo de Consentimento Livre e Esclarecido.

Definidos os instrumentos, a coleta de dados deu-se pela aplicação do questionário no grupo de alunos e no grupo de professores. Os sujeitos foram submetidos ao sorteio simples. Cada um dos alunos selecionados por meio de sorteio respondeu ao questionário como forma de autoavaliação. Após, foram sorteados quatro professores. Esses professores sortearam aleatoriamente os alunos que estiveram sob sua supervisão durante o período de estágio. Os professores avaliaram o desenvolvimento das competências dos alunos que estiveram sob sua supervisão. Dos quatro professores, dois avaliaram sete alunos e dois professores avaliaram oito alunos, totalizando 30 questionários.

Para a análise estatística, dividimos os dados obtidos em três dimensões: a dimensão aluno, a dimensão professor e a dimensão que compara os dados obtidos dos alunos e dos professores. Para a análise dos dados da dimensão aluno e da dimensão professor, o estudo estatístico foi realizado em duas etapas.

Na primeira etapa o estudo descritivo foi realizado basicamente através de tabelas de distribuição e gráficos de barras e de setores, para todas as questões constantes no questionário para coleta de dados das dimensões aluno e professor. Para a segunda etapa foi necessária a utilização de métodos estatísticos não-paramétricos, o teste de Jonckheer-Terpstra, que detecta diferença entre grupos por meio de ranqueamento ${ }^{10}$. Nesse estudo os três níveis de frequência de realizações das ações que compõem a competência ("Nunca realizou", "Realizou algumas vezes" e "Realizou com muita frequência") foram consideradas como tratamentos. 
O princípio utilizado para a análise dos dados se deu baseado na frequência de realizações das ações agrupadas em cada uma das seis competências, ou seja, procuramos evidências estatísticas que pudessem comprovar se as ações realizadas com mais frequência pelos alunos também foram as ações que apresentaram significância estatística, justificando ou não o desenvolvimento da competência ao qual estava relacionada.

$O$ aluno foi avaliado de duas maneiras: por meio de autoavaliação em que eles se atribuíram notas de 1 a 5 (sendo um para aqueles que não se consideram preparados e 5 para aqueles que se consideram completamente preparados). E por meio da avaliação de professores que os acompanharam, refletindo acerca das ações realizadas atribuindo notas ao preparo do aluno com relação a cada uma das seis competências. A análise estatística comparou as notas atribuídas para a competência atenção à saúde com os grupos que afirmaram ter realizado determinada ação com muita frequência.

A significância estatística $(p<0,05)$ foi verificada ao cruzar as notas atribuídas por cada aluno com os grupos: realizou muitas vezes, realizou algumas vezes ou nunca realizou ${ }^{10}$. 0 objetivo foi identificar se as ações que os alunos realizaram com muita frequência (mais treinados) foram aquelas que eles se sentiram mais aptos a desenvolvê-las no seu dia a dia de trabalho.

A análise de comparação entre a visão dos alunos e a visão dos professores se deu por meio do estudo através de métodos paramétricos. Na comparação entre a visão dos alunos e a visão dos professores, foi utilizado o teste da igualdade das médias através do teste " $t$ " e para detectar a igualdade da variabilidade das respostas na visão dos sujeitos a análise realizada contou com o teste "F". Após a identificação oferecida pelo teste " $F$ " no que diz respeito à variabilidade aplicou-se o teste " $\mathrm{t}$ " para a verificação das igualdades das médias ${ }^{10}$.

A análise qualitativa das perguntas abertas se deu da seguinte forma: organização do material, dividindo-os em partes, relacionando estas partes e procurando identificar nele tendências e padrões relevantes. Num segundo momento essas tendências e padrões foram reavaliados, buscando as relações e interferências num nível de abstração mais elevado ${ }^{11}$.

\section{RESULTADOS}

$\mathrm{Na}$ dimensão aluno, todos os discentes que participaram da pesquisa afirmaram que foram estimulados a desenvolverem a competência atenção à saúde durante o ECS. E ao término, a maioria deles $(66,6 \%)$ relata se sentir completamente ou muito preparados para realizar ações voltadas a esta competência no seu dia a dia de trabalho, como mostra a Tabela 1.

Tabela 1. Preparo para realizar a competência atenção à saúde, segundo o olhar do aluno.

\begin{tabular}{lcc}
\hline Grau de preparação & Freq. & $\%$ \\
\hline Não se considera preparado & 0 & 0 \\
Pouco preparado & 0 & 0 \\
Preparado de forma razoável & 10 & 33,3 \\
Muito preparado & 16 & 53,3 \\
Completamente preparado & 4 & 13,4 \\
\hline
\end{tabular}

A maioria dos alunos afirma ter realizado com muita frequência, três ações que caracterizam a atenção à saúde, sendo elas: ações de prevenção à saúde, ações de promoção à saúde e atividades com caráter técnico $(93,3 \%$, $86,7 \%$ e $70,0 \%$, respectivamente).

Considerando que cada aluno se atribuiu uma nota de 1 a 5 (nota 5 completamente preparado e nota 1 não se considera preparado) referente ao preparo para realizar ações de atenção à saúde, as ações que foram estatisticamente significativas para justificar o preparo do aluno não estiveram, necessariamente, relacionadas às ações que os mesmos afirmam ter sido realizadas com mais frequência. Desse modo, acreditava-se que as ações que seriam mais significantes seriam aquelas que os alunos teriam treinado mais, porém ao compararmos as notas que eles se atribuíram para cada uma das competências, com o grupo de alunos que afirmam ter realizado as ações com muita frequência, as ações que foram significativas, não necessariamente foram aquelas que eles mais praticaram.

Consideramos como grupos ou tratamento, as alternativas que os alunos assinalaram: nunca realizou, realizou algumas vezes e realizou com muita frequência as ações descritas no questionário. A significância estatística $(p<0,05)$ se deu ao cruzar as notas atribuídas por cada aluno com os grupos: realizou muitas vezes, realizou algumas vezes ou nunca realizou. 
Portanto, embora as ações - relação com outros serviços da rede e resolutividade de problemas em âmbito individual e/ou coletivo não ter sido muito realizada pela maioria dos participantes da pesquisa, ou seja, 20,0\% e $36,7 \%$, os alunos que realizaram com muita frequência estas ações apresentaram significância na estatística. Desse modo, nossa análise identificou que os poucos alunos que realizaram estas duas ações com muita frequência se atribuíram notas melhores do que aqueles que afirmam ter realizado algumas vezes ou que nunca realizaram.
Somente a ação - atividades com caráter técnico - estava entre as ações que os alunos realizaram com muita frequência $(70,0 \% ; p<0,05)$, pois o grupo de alunos que afirmam ter realizado com muita frequência esta ação se atribuíram notas melhores do que o grupo que realizou algumas vezes ou nunca realizou. A Tabela 2 apresenta os resultados estatísticos que buscou justificar o desenvolvimento da competência atenção à saúde.

Tabela 2. Ações descritas nas DCNs que buscaram justificar o desenvolvimento da competência atenção á saúde segundo a visão dos alunos.

\begin{tabular}{|c|c|c|c|c|}
\hline & Nunca realizou & $\begin{array}{c}\text { Realizou algumas } \\
\text { vezes }\end{array}$ & $\begin{array}{c}\text { Realizou com } \\
\text { muita frequência }\end{array}$ & $\mathbf{p}$ \\
\hline Prevenção à saúde & $0 \%(0)$ & $6,7 \%(2)$ & $93,3 \%(28)$ & \\
\hline Promoção à saúde & $0 \%(0)$ & $13,3 \%(4)$ & $86,7 \%(26)$ & \\
\hline Proteção à saúde & $0 \%(0)$ & $36,7 \%(11)$ & $63,3 \%(19)$ & \\
\hline Reabilitação à saúde & $3,3 \%(1)$ & $43,3 \%(13)$ & $53,3 \%(16)$ & \\
\hline $\begin{array}{l}\text { Relação com outros serviços da rede de } \\
\text { saúde }\end{array}$ & $3,3 \%(1)$ & $76,7 \%(23)$ & $20,0 \%(6)$ & $*$ \\
\hline $\begin{array}{l}\text { Resolutividade de problemas em âmbito } \\
\text { individual e/ou coletivo }\end{array}$ & $6,7 \%(2)$ & $56,7 \%(17)$ & $36,7 \%(11)$ & $*$ \\
\hline Atividades com caráter técnico & $0 \%(0)$ & $30,0 \%(9)$ & $70,0 \%(21)$ & $*$ \\
\hline $\begin{array}{l}\text { Atividades de caráter puramente } \\
\text { reflexivas }\end{array}$ & $3,3 \%(1)$ & $50,0 \%(15)$ & $46,7 \%(14)$ & \\
\hline $\begin{array}{l}\text { Conhecimento do perfil da clientela } \\
\text { interna e externa }\end{array}$ & $0 \%(0)$ & $44,8 \%(13)$ & $55,2 \%(16)$ & \\
\hline
\end{tabular}

* Teste de Jonckheere-Terpstra: $p<0,05$.

Ao término das questões fechadas, os alunos responderam, de forma escrita, a seguinte pergunta: para você, o ECS contribuiu para o desenvolvimento da competência atenção à saúde? Por quê?

Por meio desta questão, foi possível identificar as relações que os alunos fazem entre a competência atenção à saúde, à profissão e ao trabalho. Dois pontos tiveram destaque na fala dos alunos, sendo eles: a relação entre a competência atenção à saúde e a aproximação com a assistência de enfermagem e o sentimento de liberdade proporcionada pela dinâmica do estágio, permitindo que os alunos mobilizem seus recursos de forma autônoma, sem a interferência direta do docente, mas percebendo seu apoio.
A aproximação da competência com a função assistencial do enfermeiro pode ser evidenciada por meio dos seguintes relatos:

"...foi uma das competências mais desenvolvidas, pois a assistência ao paciente é uma ação bem forte da profissão" (aluno 3)

"motiva os alunos a cuidar do paciente de forma a orientá-lo, preveni-lo de certas coisas e ajudá-los a promover a saúde" (aluno 15).

"nos fez propor ações para resoluções de coisas que aconteciam na unidade ou com pacientes e também para melhorar outras ações" (aluno 17).

Percebe-se que a sensação de liberdade os levou a mobilizar recursos pessoais, a experimentar o mundo do trabalho como ele realmente é, sem controles ou cortes, 
vivenciando as funções das enfermeiras, ampliando o olhar para questões que vão além das teorias e com isso, tornando-os mais reflexivos.

"me deu uma visão melhor de cada competência e a atenção à saúde foi a que mais desenvolvi" (aluno 3).

"me sinto mais preparada depois de ter feito o ECS, pois sem o acompanhamento do professor em tudo que eu fiz me fez aprender melhor e também me fez ver que posso me virar sozinha" (aluno 9).

"me fez trabalhar de forma mais elaborada, reflexiva" (aluno 11).

Para o professor, $96,7 \%$ dos alunos entraram em contato com a competência atenção à saúde no dia a dia do ECS. Quando questionados se ao término do estágio, o aluno estava preparado para desenvolver essa competência, identificamos que a opinião do professor se apresentou bem dividida, pois afirmam que $50 \%$ dos alunos se encontram preparados de forma razoável e $46,7 \%$ deles se encontram muito preparados, como mostra a Tabela 3.

Tabela 3. Preparo para realizar a competência atenção à saúde, segundo o olhar do professor.

\begin{tabular}{lcc}
\hline Grau de preparação & Freq. & $\%$ \\
\hline Não se considera preparado & 0 & 0 \\
Pouco preparado & 0 & 0 \\
Preparado de forma razoável & 15 & 50,0 \\
Muito preparado & 14 & 46,7 \\
Completamente preparado & 1 & 3,3 \\
\hline
\end{tabular}

O professor afirma que três duas ações que caracteriza atenção à saúde foram estiveram entre as que a maioria dos alunos realizou com muita frequência, sendo elas: conhecimento da clientela interna e a externa, ações de promoção à saúde e ações de prevenção à saúde $(76,7 \%$; $53,3 \%$ e $50,0 \%$; respectivamente).

Considerando a nota que o professor atribuiu ao aluno, as ações que foram estatisticamente significativas para justificar 0 preparo do aluno não estiveram, necessariamente, relacionadas às ações que foram mais realizadas pelos alunos.

As ações que apresentaram significância estatística na visão do professor foram: ações de promoção à saúde, ações de reabilitação à saúde, ações que levassem à resolutividade de problemas em âmbito individual e/ou coletivo e atividades puramente reflexivas. A significância estatística se deu, pois para os professores, os alunos que realizaram estas quatro ações com muita frequência mereceram notas melhores do que aqueles que as realizaram algumas vezes ou que nunca as realizaram. Sendo assim, embora poucos alunos tenham realizado essas ações com muita frequência, eles estariam mais preparados para desenvolver a competência atenção à saúde do que a maioria dos alunos que realizou essa ação algumas vezes, pois os professores atribuíram notas melhores.

Dentre as ações significativas para o professor, somente a ação de promoção à saúde estava entre as três ações que a maioria dos alunos $(53,3 \%)$ realizou com muita frequência. A Tabela 4 apresenta os resultados estatísticos que buscaram justificar o desenvolvimento da competência atenção à saúde.

Ao término das questões fechadas, o questionário propunha que o professor analisasse o desempenho do aluno durante todo o ECS e respondesse de forma aberta se, na sua visão, o ECS havia contribuído para o desenvolvimento da competência atenção à saúde para aquele determinado aluno.

Observamos que para os professores o ECS permitiu que o aluno desenvolvesse a competência atenção à saúde. Analisando os discursos, dois fatores foram muito importantes para a ocorrência desse desenvolvimento: o interesse individual do aluno e as oportunidades oferecidas pelo campo de estágio. Esses dois fatores são evidenciados nos discursos abaixo:

"houve iniciativa por parte do aluno associado às oportunidades oferecidas pelo campo de estágio" (professor avaliando o aluno $6)$.

"o aluno se sentiu seguro e a unidade ofereceu várias situações de atenção à saúde. $O$ aluno soube aproveitar e viver cada situação profundamente" (professor avaliando o aluno 22).

No olhar do professor a participação em atividades do cotidiano do enfermeiro depende da iniciativa do aluno e também da abertura que o campo oferece ao mesmo, ou seja, mesmo havendo interesse por parte do aluno, se o campo de estágio não permitir a participação dos mesmos nas atividades do doa a dia, não haverá o desenvolvimento de ações que contribuam para a construção das competências profissionais. 
Tabela 4. Ações descritas nas DCNs que buscaram justificar o desenvolvimento da competência atenção á saúde segundo a visão dos professores.

\begin{tabular}{lcccc}
\hline & Nunca realizou & $\begin{array}{c}\text { Realizou } \\
\text { algumas vezes }\end{array}$ & $\begin{array}{c}\text { Realizou com } \\
\text { muita frequência }\end{array}$ & p \\
\hline Prevenção à saúde & $16,7 \%(5)$ & $33,3 \%(10)$ & $50,0 \%(15)$ \\
Promoção à saúde & $0 \%(0)$ & $46,7 \%(14)$ & $53,3 \%(16)$ & $*$ \\
Proteção à saúde & $0 \%(0)$ & $70,0 \%(21)$ & $30,0 \%(9)$ & $*$ \\
$\begin{array}{l}\text { Reabilitação à saúde } \\
\text { Relação com outros serviços da rede de saúde }\end{array}$ & $33,3 \%(10)$ & $33,3 \%(10)$ & $33,3 \%(10)$ & $* 13,3 \%(4)$ \\
$\begin{array}{l}\text { Resolutividade de problemas em âmbito } \\
\text { individual e/ou coletivo }\end{array}$ & $0 \%(0)$ & $60,0 \%(18)$ & $40,0 \%(12)$ & $*$ \\
$\begin{array}{l}\text { Atividades com caráter técnico } \\
\text { Atividades de caráter puramente reflexivas }\end{array}$ & $0 \%(0)$ & $76,7 \%(23)$ & $23,3 \%(7)$ & $*$ \\
$\begin{array}{l}\text { Conhecimento do perfil da clientela interna e } \\
\text { externa }\end{array}$ & $0,7 \%(2)$ & $63,3 \%(19)$ & $30,0 \%(9)$ & $76,7 \%(23)$
\end{tabular}

* Teste de Jonckheere-Terpstra: $P<0,05$.

Após analisarmos os dados obtidos por meio do questionário que foi respondido tanto pelo professor quanto pelo aluno, esta pesquisa partiu para a comparação dos dados de ambos os sujeitos com a intenção de desvendar se houve posição dialética entre eles.

Neste momento da análise dos dados, buscamos comparar as notas atribuídas pelos professores (que avaliaram o desempenho do aluno) e pelos alunos (que se autoavaliaram), a fim de identificar se as opiniões referentes a possíveis contribuições do ECS para o desenvolvimento da competência atenção à saúde foram semelhantes ou divergentes. Além disso, identificamos as ações que foram significativas para os alunos e para os professores, traçando um paralelo entre elas.

As ações que foram significativas para os professores e para os alunos não foram exatamente as mesmas. Para o aluno, três ações obtiveram significância estatística: relação com outros serviços da rede, resolutividade de problemas no âmbito individual e coletivo e atividades técnicas. Já para o professor, quatro ações foram significantes: ação de promoção à saúde, ação de reabilitação à saúde, resolutividade de problemas no âmbito individual e coletivo e atividades de caráter reflexivas.

Observamos que apenas a ação resolutividade de problemas no âmbito individual e coletivo foi significante para ambos. Para o professor as ações de promoção e reabilitação (sintonizados aos princípios do Sistema Único de Saúde - SUS) podem tornar o aluno competente na atenção à saúde e o aluno entende que, apesar de ter realizado pouco, estabelecer relações com outros serviços da rede de saúde, também pode torná-lo apto a desenvolver esta competência.

Ao avaliar as médias das notas atribuídas pelos professores e alunos, observamos que elas estão muito próximas. A média das notas dos professores foi 3,5 , enquanto que a média das notas que os alunos se auto atribuíram foi 3,8 (em escala de 1 a 5). As Tabela 1 e 3 mostram as notas que os alunos se autoatribuíram e as notas que os professores atribuíram aos mesmos. Como se esperava, observa-se que os alunos se consideram melhores preparados do que na visão do professor.

\section{DISCUSSÃO}

Quando utilizamos testes estatísticos para comparar as notas atribuídas pelos sujeitos, identificamos que para a competência Atenção à Saúde não há evidências de diferença entre as notas atribuídas (professores e alunos). $O$ teste " $\mathrm{t}$ " mostra que as médias atribuídas pelos professores $(3,5)$ das médias atribuídas pelos alunos $(3,8)$ não são estatisticamente diferentes.

Este fato deixa claro que no desenvolvimento da competência do cuidar, ou 
seja, na competência Atenção à Saúde alunos sentem que foram preparados na mesma proporção que os professores afirmaram terem preparado seus alunos.

Procurando compreender 0 desenvolvimento de competências por meio de ações realizadas no cotidiano do enfermeiro e que pudessem garantir habilidades necessárias para o desenvolvimento profissional do aluno, observamos que as competências vão além da realização repetitiva de determinadas habilidades. Seu desenvolvimento requer um conhecimento aprofundado de concepções, métodos e objetivos que se almejam alcançar.

Considerando que este estudo partiu da compreensão que os pesquisadores possuem das DCNs, acreditamos que elas são uma síntese das perspectivas de diferentes atores envolvidos com a formação profissional ${ }^{12}$. E, embora traga em seu texto os elementos e as dimensões dos novos perfis profissionais almejados, no documento, não há nenhuma explicação da concepção de competência utilizada, existindo ainda certa confusão no emprego dos termos competências e habilidades.

A análise dos dados nos fez refletir acerca do caráter de cada ação, seu significado para os sujeitos e da capacidade de mobilizar recursos (cognitivos, psicomotores e afetivos) ${ }^{6}$ que os alunos desenvolveram para sua realização, pois as ações que possuíam caráter meramente técnico (como por exemplo: conhecimento do perfil da clientela interna e a externa), embora tenha sido realizada com muita frequência pela maioria dos alunos (tanto na visão do professor quanto na visão dos alunos) não foram estatisticamente significativas.

Da mesma forma que ações que necessitaram da mobilização de recursos pessoais, que não estivessem apenas voltados para habilidades (como por exemplo: resolutividade de problemas de saúde em âmbito individual e coletivo) foram significantes tanto para os professores quanto para os alunos, embora poucos alunos tenham realizado com muita frequência.

Então, o que há nessas ações que fazem com que se tornem significantes para quem as realiza? $O$ que elas significam para 0 desenvolvimento das competências? Existem ações pedagógicas que possam contribuir para que ações do cotidiano de trabalho torne o profissional competente?
Desta forma destacamos que a aquisição de habilidades só será possível se os sujeitos tiverem tempo de viver as experiências e capacidade de analisar sua construção criticamente. Uma coisa é colocar várias ações em prática com o objetivo de adquirir conhecimentos, sem preocupar-se em mobilizálos de forma sistemática, confiando apenas no seu desenvolvimento no decorrer a vida. E outra coisa é estabelecer quais os conhecimentos são necessários para desenvolver determinada ação, com o objetivo de refletir sua mobilização em situações reais, na dialética da ação-reflexãoação ${ }^{7}$.

A aplicação da noção de competência implica em realizar novas formas de educar/formar os futuros trabalhadores e integrar inteiramente os sujeitos envolvidos com a proposta (instituição de nível superior, professor, aluno, profissionais de campo e instituição de saúde envolvida) com o objetivo de comprometê-los ao processo de ensino/aprendizagem proposto ${ }^{13}$.

É importante ressaltar também que o desenvolvimento das competências profissionais não compete somente aos envolvidos com o ECS. Toda a organização curricular deve focalizar o desenvolvimento das competências com a integração e exploração dos conteúdos a partir de situações reais ou simuladas da prática profissional. Essas situações representam estímulos para o desencadeamento do processo ensino/aprendizagem. As situações reais, os vínculos criados com pacientes, com as equipes de saúde e com a própria organização e avaliação dos serviços que foram prestados são considerados fundamentais para a construção das competências ${ }^{13}$.

Entretanto fica ainda uma pergunta a ser respondida: o que faz uma ação ser significante? Acreditamos que para responder a esta pergunta é necessário que novas pesquisas sejam realizadas para aprofundar ainda mais a temática. Investigar o que está por trás das ações significantes é um estímulo para os profissionais que têm como objetivo levar o aluno a desenvolver suas habilidades e competências.

\section{CONCLUSÃO}

E ao término dessa pesquisa afirmamos que a hipótese que mobilizou esta investigação não foi confirmada, pois os dados obtidos mostraram que as ações mais realizadas, não necessariamente foram aquelas que professores 
e alunos sinalizaram como significativas. Houve ações que foram realizadas com muita frequência por poucos alunos, mas que se tornaram significativas devido ao fato destes poucos alunos terem se atribuído notas melhores do que os demais. Isso aconteceu também na análise dos dados obtidos por meio da avaliação dos professores, onde os mesmos colocam que poucos alunos realizaram com muita frequência determinada ação, mas esses poucos alunos mereceram notas melhores do que os demais.

Enfim, a compreensão do ECS enquanto colaborador do desenvolvimento de competências é verdadeiro, desde que as propostas e as estratégias a serem viabilizadas sejam do domínio de todos os envolvidos nesse processo, a começar pela escola. Não se trata de tarefa fácil, mas o desafio está lançado!

\section{CONFLITOS DE INTERESSE}

Os autores declaram não haver qualquer potencial de conflito de interesse que possa interferir na imparcialidade deste trabalho científico.

\section{REFERÊNCIAS}

1. Brasil. Conselho Nacional de Educação. Câmara de Educação Superior. Resolução CNE/CES n.o 3, de 7 de novembro de 2001. Institui Diretrizes Curriculares Nacionais do Curso de Graduação em Enfermagem. Brasília (DF): Ministério da Educação e Cultura, 2001.

2. Brasil. Ministério da Educação. Lei de Diretrizes e Bases da Educação Nacional. Lei n. 9394/96. Brasília, DF: MEC/SEF, 1996.

3. Esteves LSF, Sabia CPP. Estágio curricular supervisionado: possíveis contribuições para o desenvolvimento das competências do profissional enfermeiro. [Dissertação]. Programa de Pós-Graduação em Educação, Universidade do Oeste Paulista, Presidente Prudente. 2011. 198f.
4. Almeida MA. Concepções de discentes e docentes sobre competências na enfermagem. Rev Gaúcha Enferm. 2004;25(2):184-93.

5. Rovai E. Competência e competências: contribuição crítica ao debate. São Paulo: Cortez; 2010.

6. Tsuji $\mathrm{H}$, Silva HA. Aprender e ensinar na escola vestida de branco: do modelo biomédico ao humanístico. São Paulo: Phorte Editora; 2010.

7. Perrenoud P. Construir competências desde a escola. Porto Alegre: Artes Médicas Sul; 1999.

8. Peres AM, Ciampone MHT. Gerência e competências gerenciais do enfermeiro. Texto e Contexto Enferm. 2006;15(3):492-9. https://doi.org/10.1590/S010407072006000300015

9. Minayo MCS. O desafio do conhecimento: pesquisa qualitativa em saúde. 8.ed. São Paulo: Hucutec; 2004.

10. Melem VM. Testes de hipóteses. Londrina: Departamento de Estatística, UEL; 2010.

11. Bardin L. Análise de conteúdo. 4.ed. Lisboa: Edições 70; 2009.

12. Lima VV. Competência: distintas abordagens e implicações na formação de profissionais de saúde. Interface - Comun Saúde Educ. 2005;9(17):369-79. DOI: https://doi.org/10.1590/S1414-

32832005000200012

13. Silva KL, Sena RR. A educação de enfermagem: buscando a formação críticoreflexiva e as competências profissionais. Rev Latino-Am Enferm. 2006;14(5):755-61. DOI: http://dx.doi.org/10.1590/S0104$\underline{11692006000500018}$

Recebido para publicação em 02/07/2015

Revisado em 01/10/2016

Aceito em 24/05/2017 